\title{
Physio-Chemical and Sensorial Quality Evaluation of Commercially Available Dried Apricots of Gilgit Baltistan, Pakistan
}

\author{
Naveed Hussian ${ }^{1}$, Muhammad Shahnawaz ${ }^{1}$, Yawar Abbas $^{2}$, Nawazish Ali ${ }^{1}$, Tanveer Abbas ${ }^{1}$, \\ Sami Ullah $^{3}$, Attarad Ali ${ }^{4}$, Altaf Hussain ${ }^{1}$ \\ ${ }^{1}$ Department of Agriculture and Food Technology, Karakoram International University, Gilgit, Pakistan \\ ${ }^{2}$ Department of Earth \& Environmental Sciences, Bahria University, Islamabad, Pakistan \\ ${ }^{3}$ Department of Agronomy, Agriculture University, Faisalabad, Pakistan \\ ${ }^{4}$ Department of Biotechnology, Quaid-i-Azam University, Islamabad, Pakistan
}

\section{Email address:}

naveed_kiu@yahoo.com (N. Hussain),dr.shahnawaz@kiu.edu.pk (M. Shahnawaz),yawar_zaid@yahoo.com (Y. Abbas), amjadmalik747@gmail.com (N. Ali), abbasglt110@gmail.com (T. Abbas), samisheen14@gmail.com (S. Ullah),

mellow_786@yahoo.com (A. Hussain)

\section{To cite this article:}

Naveed Hussian, Muhammad Shahnawaz, Yawar Abbas, Nawazish Ali, Tanveer Abbas, Sami Ullah, Attarad Ali, Altaf Hussain. PhysioChemical and Sensorial Quality Evaluation of Commercially Available Dried Apricots of Gilgit Baltistan, Pakistan. Journal of Food and Nutrition Sciences. Vol. 3, No. 6, 2015, pp. 216-222. doi: 10.11648/j.jfns.20150306.13

\begin{abstract}
The purpose of current study is to evaluate the physicochemical characteristics and sensory evaluation in some varieties of dried apricot from Gilgit-Baltistan. Dried apricots of four different varities (Margulam. Halman, Habi and Khakas) were analyzed for the physicochemical characteristics and sensory evaluation. Maximum total ash was found in Halman, $(3.336 \%)$ and minimum ash found in Margulam (2.467\%). The maximum titratable acidity was in Habi $(0.33 \%)$ and minimum in Khakas $(0.316 \%)$. Crude fat was found maximum in Margulam (1.650 \%) and minimum in Halman $(1.236 \%)$. The crude fiber content was maximum in Habi (3.316\%) and minimum in Khakas (1.246 \%). Margulam (89.300 \%) and minimum in Habi (86.267 \%).Higher scores were assigned for taste, texture, and overall acceptability (7.400), (7.200) and ((7.200) respectively for Halman variety of apricot. The color score was maximum in Khakas (8.200) and minimum in Habi (6.400) while other varieties ranged (6.433 to 7.233). The maximum texture score in Halman (7.200) and minimum in Habi (6.00) while other varieties ranged (6.33 to 6.500).The taste score was maximum in Halman (7.400) and minimum in Habi (6.00) while other varieties ranged (6.200 to 6.36). Overall acceptability maximum scores for Halman (7.200) minimum in Khakas (6.33). Analysis of variance pertaining to moisture contents, dry solids, crude fibers and ascorbic acids were apparent from the result they differed significantly among different varieties. The mean value for ash content, $\mathrm{pH}$, crude fat and titratable acidity revealed non-significant effect among varieties of dried apricots.
\end{abstract}

Keywords: Physio-Chemical, Nutrition, Sensory Evaluation, Dry Apricot

\section{Introduction}

Pakistan is blessed with fertile lands and environment for the growth of fruits and vegetables round the year. GilgitBaltistan is blessed with the production of natural resources. Geographical diversity of the region ensures growth of a broad variety of fruits including mango, citrus, apple, strawberry, apricot etc. Domestically, prospect to increase fruit production is at the high probably due to profits associated with the fresh produce (Ali et al.,
2011).Apricot (Prunusarmeniaca L.) is member of Rosaceae family and one of the most significant drupe fruits of temperate regions. It is considered to be the native of China and has been cultivated for over 4000 years. Pakistan stands $3^{\text {rd }}$ among major producer of apricot and the annual production is 0.5 million Mt (FAO, 2008; DOA, 2008). Apricots contain minerals like ( $\mathrm{K}, \mathrm{Na}, \mathrm{Ca}, \mathrm{Fe}, \mathrm{Co}$, $\mathrm{Zn}$ ), sugars, bioactive phyto chemicals, andvitamins such as $\mathrm{A}, \mathrm{C}, \mathrm{E}, \mathrm{B}_{1}, \mathrm{~B}_{2}, \mathrm{~B}_{3}$ and $\mathrm{B}_{5}$ (Lecceseet al, 2007). Apricot also contains Phytochemicals, carotenoids, phenolics, carotenoids, and antioxidants which have great importance 
in increasing the immunity system of human against many diseases and may act as anti-fever, mild laxative, cleansing agent, antiseptic, anti-vomiting and against eye diseases (Lichouet al., 2003; Lila, 2004; Dragovicet al., 2007; Enomoto et al., 2010). Different Preservation methods such as canning, freezing, drying and controlled atmosphere packaging have been developed for the extending life of fruit (Jimenez et al., 2008). 40-45(\%) is processed (Madrauet al, 2009). Apricot is preserved mainly by conventional method like sun drying without any chemical treatment. In Gilgit-Baltistan, dried apricot can be purchased whole year, while the fresh fruit comes in the market by end of May to September (Faqiret al., 2004). This process is not suitable as provides uneven dark color and hard texture, microbial attack also contributes wastage of fruit, hence, wastage is high or used as fodder due to lack of proper facilities to preserve and market this fruit (Anonymous, 2004). As sun drying is one of the oldest methods of preservation of food materials and it is in used from prehistoric times. Fruits having high moisture can easily spoiled and so they must be treated as soon as possible to save any harvest loss (Barsottiet al., 1999). For the high quality dried apricot under hygienic conditions solar energy are used in cabinet or tunnel drier (Singh and Thapar, 1990).

Mismanagement leads to inadequate yields of crops and fruits and the harvest losses account for about $25-40 \%$ of the total production thereby leading to greater financial loss for the country (GOP, 2008). Fruit harvested at the commercial stage never reached the quality of mature harvested fruit. They suggested that selection should be directed towards fruit with acceptable post-harvest behavior. According to a survey the total apricot production of Pakistan was 193.9 metric tons (PBS, 2011). The destined semi dried apricots are then put to sun drying for 5-6 days. In Turkish method with $\mathrm{SO} 2$ the apricots are placed in wooden trays covered the trays with plastic tent and sulphur fumes are smoked in plastic tent by a sulphur fumigator for 4-5 hours for sun drying (AKRSP, 1999). It is reported that due to lack of know-how, 50-70\% fruits goes wasted in Gilgit-Baltistan. In the glut season of this particular fruit, a big amount of fruit is being wasted, due to its perishable nature and limited marketing. This loss is as higher as $44 \%$ of the total production (FAO, 2008). Locally grown fruit was dried to water content of 16-20 (\%) by using a shelf drier and subjected to sensorial tests. All the apple, cherry and pear cultivars tested gave good results, but apricots had a sour taste (Samann, 1991). An ancient technique is solar dehydration which is very suitable for tropical countries where abundant of radiation is available also this energy is freely available for domestic use. It is easy and useful for rural areas where a lot of commodity is lost as a result of deterioration and spoilage (Taiwoet al., 2001). the Osmotic dehydration process produces minor changes in the nutritional and sensory quality of the foods producing minimally produced foods along with food that are retaining much of the properties of the original foods
(Shi et al., 2004). Apricots contains rich amount of $\beta$ carotene which has a health promoting effects, it strengthen body to fight against diseases, helps in develop bones and teeth, keeps skin, gums, hairs, healthy also protects eye (shahidi and Naczk, 1995).

\section{Material and Methods}

\subsection{Study Area}

Four different varieties of dried apricot (Margulam, Halman, Habi and Khakas) which are commercially available in Gilgit-Baltistan were purchased and were brought to Food Science and Product Development Institute, National Agriculture Research Center, Islamabad. The samples were sorted, damaged ones are removed and good ones are selected. These samples were preserved and sealed in polythene bags. The dried apricot was passed through a number of tests to determine the different quality attributes of each variety. The tests that were carried out are moisture content, ash content, crude fat, crude fiber, titratable acidity, $\mathrm{pH}$, dry solids, and ascorbic acid.

\subsection{Pre-treatment of Raw Material}

Samples were crushed prior to analysis and each sample was packed in striper polyethylene bags with the following abbreviations:

Table 1. Sample abbreviations and Local names of dry Apricot.

\begin{tabular}{ll}
\hline Varieties & Local Names \\
\hline V1 & Margulam \\
V2 & Halman \\
V3 & Habi \\
V4 & Khakas \\
\hline
\end{tabular}

\subsection{Physio-Chemical Analysis}

\subsubsection{Moisture Content}

The moisture of fruit samples were determined by following the method described by AOAC (2000). In this regard, the sample material were taken in a flat-bottom dish (pre-weighed) and kept overnight in an oven at 100-110 ${ }^{0}$ Cand weighed. The loss in weight was regarded as a measure of moisture content. The following formula was used to calculate the moisture content;

$$
\text { Moisture } \%=\frac{\text { Wt. of fresh sample }- \text { Wt. of sample after drying }}{\text { Wt. of fresh Sample }} \times 100
$$

\subsubsection{Ash Content}

For determination of ashcontent method of AOAC (2000) was followed. According to the method, $10 \mathrm{~g}$ of each sample was weighed in a silica crucible. The crucible was heated in a muffle furnace for about 3-5 hours at $500{ }^{\circ} \mathrm{C}$. It was cooled in desiccator and weighed to ensure completion of ashing, it was reheated again in the furnace for half an hour more, cooled and weighed. This process was repeated consequently till the weight become constant (ash become white or grayish white). Weight of ash gave the ash content and was 
calculated by the following formula

$$
\text { Ash }(\%)=\frac{\text { Wt. of ash }(\mathrm{g})}{\text { Wt. of sample }(\mathrm{g})} \times 100
$$

\subsection{Determination of Titratable Acidity}

The standard method of AOAC (2006) was used to determine the Titratable Acidity (\%) of the dried apricot samples.

\subsection{Reagents}

1. Oxalic acid

2. Distilled water

3. $\mathrm{NaOH}$

\subsection{Preparation of Solution to Standardize of $0.1 \mathrm{~N} \mathrm{NaOH}$}

Distilled water volume of 1 liter was taken and oxalic acid (6.3g) was dissolved in distilled water. Pellets of $\mathrm{NaOH}(4.5$ g) were taken and set to dissolved in distilled water and made I liter of volume. Add 2 drops of phenolphthalein for indictor and $10 \mathrm{ml}$ of $0.1 \mathrm{~N}$ oxalic acid were taken in a conical flask. Approximately ready $0.1 \mathrm{~N} \mathrm{NaOH}$ was taken in burette. The contents of the flask were titrated against $0.1 \mathrm{~N} \mathrm{NaOH}$ solutions until pink color which was light appeared. By using formula $\mathrm{NaOH}$ normality was adjusted and consecutively four readings were taken.

Formula

$$
\mathrm{N}_{1} \mathrm{~V}_{1}=\mathrm{N}_{2} \mathrm{~V}_{2}
$$

$$
\begin{aligned}
& \mathrm{N}_{1}=\text { oxalic acid normality } \\
& \mathrm{V}_{1}=\text { oxalic acid volume } \\
& \mathrm{N}_{2}=\mathrm{NaOH} \text { normality of } \mathrm{V}_{2}=\mathrm{NaOH} \text { volume }
\end{aligned}
$$

\subsection{Titration of Samples}

$10 \mathrm{~g}$ sample was taken in a diluted with distilled water in $100 \mathrm{ml}$ conical flask and carefully blended and filtered by filter paper. $10 \mathrm{ml}$ of these diluted samples were taken in titration flask and added two or four drops of phenolphthalein as indicator and then titration was carried out against exact $0.1 \mathrm{NaOH}$ solution, until light pink color appeared. Four consecutive readings were taken.

Calculations were made for titratable acidity of the samples by using following formula.

$$
\text { Acidity }(\%)=\frac{\mathrm{C} . \mathrm{F} \times \mathrm{N} \times \text { ml of } \mathrm{NaOHused} \times 100 \times 100}{\mathrm{~A} \times \mathrm{B}}
$$

Where,

C.F $=$ Correction Factor and for citric acid is 0.064

$\mathrm{A}=$ Samples for titration

$\mathrm{B}=$ Samples for dilution

$\mathrm{N}=$ Normality of $\mathrm{NaOH}$

\subsection{Determination of $\mathrm{pH}$}

For determination of $\mathrm{pH}$ in the products, a method of
AOAC (2000) was adopted and digital $\mathrm{pH}$ meter was used. The $\mathrm{pH}$ meter was calibrated with buffers at $\mathrm{pH} 4$ and $\mathrm{pH} 10$. Sample solution was taken in the beaker and inserted. When the first reading was completed, the electrode was washed with distilled water and dried-up with tissue paper. Similarly, as a continue series, all other samples were determined accordingly.

\subsection{Determination of Crude Fat}

Two gram sample of dried apricot was weight into a preweight filter paper $\left(\mathrm{W}_{1}\right) .50 \mathrm{ml}$ solvent (petroleum ether) was added to a cup which was attached to the extraction unit. The sample was subjected to extraction of oil with solvent by solvent by rinsing for 2 hours.

The sample was removed, dried in an oven at $105^{\circ} \mathrm{C}$ for 1 hour and weight $\left(\mathrm{W}_{2)}\right.$. Crude fat was calculated by using the following formula:

$$
\text { Crude fat }(\%)=\mathrm{Wt} \text { of ether extract } / \mathrm{wt} \text { of sample } \times 100
$$

\subsection{Determination of Crude Fiber}

The sample after fat extraction was analyzed for crude fiber by the following procedure mentioned in AACC (2000) method No.32-10. The crude fiber was determine in $2 \mathrm{~g}$ fat free sample and digested with $200 \mathrm{ml}$ boiling $1.25 \% \mathrm{H}_{2} \mathrm{SO}_{4}$, filtered and washed thrice. Then sample was again digested with $200 \mathrm{ml}$ of boling $1.25 \% \mathrm{NaOH}$ for 30 mintutes, filtered and washed thrice. The resultant residue was dried at $130^{\circ} \mathrm{C}$ for 2 hours and weighed $\left(\mathrm{W}_{1}\right)$. Dried residue was ignited at $600^{\circ} \mathrm{C} \pm 15^{\circ} \mathrm{C}$, cooled and reweighed (W2). The crude fiber was calculated according to the following expression:

$$
\text { Crude fiber }(\%)=\mathrm{W} 1-\mathrm{W} 2 / \text { weight of sample } \times 10
$$

\subsection{Determination of Ascorbic Acid}

The ascorbic acid content was estimated using 2, 6dichlorophenolindophenol dye, according to the prescribed method of AOAC (2006). Ascorbic acid reduces 2, 6dichlorophenol indophenol from light pink to a colorless solution.

\subsection{Preparation of Solutions}

Weigh $0.04 \mathrm{~g}$ dye and dissolve in distilled water to make volume to $100 \mathrm{ml}$. Weigh $0.4 \mathrm{gm}$ oxalic acid and make volume up to $100 \mathrm{ml}$

\subsection{Preparation of Standard Ascorbic Acid Solution}

Prepare $0.1 \%$ solution i.e. $10 \mathrm{~g}$ of ascorbic acid in $1000 \mathrm{ml}$ of solution.

\subsection{Procedure}

Firstly, titrate the prepared standard ascorbic acid solution and oxalic acid solution against the dye (2, 6dichlorophenolindophenol). The obtained reading served as standard. Afterwards, extracted juice sample along with oxalic acid solution was titrated against indophenol dye and 
noted the volume used.

Vitamin $\mathrm{C}$ contents will be determined using the formula as under

$$
\text { Ascorbic Acid }=\frac{1 \times R \times V}{R_{1} \times W \times V_{1}} \times 100
$$

Where, $\mathrm{R}=\mathrm{ml}$ of dye used against sample (juice) titration $\mathrm{V}=$ volume of sample diluted by oxalic acid solution

$\mathrm{R}_{1}=\mathrm{ml}$ of dye used for titration against standard ascorbic acid solution

$\mathrm{W}=$ weight of sample

$\mathrm{V}=$ volume of filtrate

\subsection{Determination of Dry solids}

Dry solids of the samples were determined by subtracting moisture content of dried apricot from 100 as reported by Lee (1975). The moisture content of each dried apricot variety was determined by the following expression:

$$
\begin{aligned}
& \text { Dry solids in } V_{1}(\%) \text { Dry solids }(\%)=100-V_{1} \\
& \text { Dry solids in } V_{2}(\%) \text { Dry solids }(\%)=100-V_{2} \\
& \text { Dry solids in } V_{3}(\%) \text { Dry solids }(\%)=100-V_{3} \\
& \text { Dry solids in } V_{4}(\%) \text { Dry solids }(\%)=100-V_{4}
\end{aligned}
$$

Where

$$
\begin{aligned}
& \mathrm{V}_{1}=\text { Margulam } \\
& \mathrm{V}_{2}=\text { Halman } \\
& \mathrm{V} 3=\text { Habi } \\
& \mathrm{V}_{4}=\text { Khakas }
\end{aligned}
$$

\subsection{Sensory Evaluation}

The samples were tested and the overall acceptability (taste, texture, color and overall acceptability) of apricot samples were evaluated on a nine point hedonic scale according to (Larmond, 1997). For sensorial assessment, fruits were served in clean transparent plates which had been labeled with random numbers. Questioners and water for mouth rinsing between each testing were provided prior to evaluation, a session was held to familiarize with the products. Panelists were asked to read through the questionnaires and the meaning of each attribute was explained to the Panelists to avoid any misinterpretation (Meligaard et al., 1991). And kilcast and Subramanian, 2000).Also interpreted the same procedure for sensorial evaluation of food products. Judges were not allowed to discuss their scores with one another during the evaluation session. The fruits then presented to the trained panel of sensory analysts. Another set of fruits were evaluated as replication by the next following day. The sensory evaluation data were presented as means of the panelist's score.

\subsection{Statistical Analysis}

All the analyses were performed in triplicate and the results were statistically processed using analysis of variance technique. The difference in means was evaluated by Least
Significant Difference Test (Steel et al., 1997).

\section{Results}

Results of the main physiochemical compositions and sensory evaluation of different varieties of dried apricot, Margulam, Halman, Habi and Khakas are shown in Tables 213.

Table 2. Determination of moisture content (\%) in different varieties of dried apricot.

\begin{tabular}{llllll}
\hline Varieties & Mean & Min & Max & S.D & CV \\
\hline V1 & $10.100 \mathrm{D}$ & 10.000 & 10.150 & 0.0866 & 0.8575 \\
V2 & $12.477 \mathrm{~A}$ & 12.420 & 12.510 & 0.0493 & 0.3954 \\
V3 & $11.423 \mathrm{~B}$ & 11.350 & 11.500 & 0.0751 & 0.6570 \\
V4 & $11.137 \mathrm{C}$ & 11.000 & 11.210 & 0.1185 & 1.0637 \\
\hline
\end{tabular}

LSD: SEC: 0.0702; CTV: 2.306; CVC: 0.1620

- All the mean values are the result of four replications

- All 2 means are significantly different from one another

Table 3. Determination of ash content (\%) in different varieties of dried apricot.

\begin{tabular}{llllll}
\hline Varieties & Mean & Min & Max & S.D & CV \\
\hline V1 & $2.4567 \mathrm{~A}$ & 2.4200 & 2.5000 & 0.0404 & 1.6451 \\
V2 & $3.3367 \mathrm{~A}$ & 3.2100 & 3.5500 & 0.1858 & 5.5694 \\
V3 & $3.2167 \mathrm{~A}$ & 3.0000 & 3.4000 & 0.2021 & 6.2820 \\
V4 & $3.3200 \mathrm{~B}$ & 3.2100 & 3.5000 & 0.1572 & 4.7338 \\
\hline
\end{tabular}

LSD: SEC: 0.1302; CTV: 2.306; CVC: 0.3002

- All the mean values are the result of four replications

- All the means carrying same alphabets are non significant at alpha $=0.05$

Table 4. Determination of pH content in different varieties of dried apricot.

\begin{tabular}{llllll}
\hline Varieties & Mean & Min & Max & S.D & CV \\
\hline V1 & $4.3833 \mathrm{~A}$ & 4.1500 & 4.5500 & 0.2082 & 6.2450 \\
V2 & $4.2667 \mathrm{~A}$ & 4.2000 & 4.4000 & 0.1155 & 2.7063 \\
V3 & $4.2500 \mathrm{~A}$ & 4.2000 & 4.3500 & 0.0866 & 0.0866 \\
V4 & $4.4333 \mathrm{~A}$ & 4.3500 & 4.5500 & 0.0153 & 2.3477 \\
\hline
\end{tabular}

LSD: SEC: 0.1118; CTV: 2.306; CVC: 0.2578

- All the mean values are the result of four replications

- All the means carrying same alphabets are non significant at alpha $=0.05$

Table 5. Mean detection of titrable acidity level (\% in terms of malic acid) in different varieties of dried apricot.

\begin{tabular}{llllll}
\hline Varieties & Mean & Min & Max & S.D & CV \\
\hline V1 & $0.3333 \mathrm{~A}$ & 0.3100 & 0.3500 & 0.0208 & 6.2450 \\
V2 & $0.3433 \mathrm{~A}$ & 0.3300 & 0.3600 & 0.0153 & 4.4491 \\
V3 & $0.3367 \mathrm{~A}$ & 0.3200 & 0.3500 & 0.0153 & 4.5372 \\
V4 & $0.3167 \mathrm{~A}$ & 0.3000 & 0.3300 & 0.0153 & 4.8238 \\
\hline
\end{tabular}

LSD: SEC: 0.0137 ; CTV: 2.306; CVC: 0.0317

- All the mean values are the result of four replications 
- All the means carrying same alphabets are non significant at alpha $=0.05$

Table 6. Mean detection of crude fiber of dride varieties of dried apricot.

\begin{tabular}{llllll}
\hline Varieties & Mean & Min & Max & S.D & CV \\
\hline V1 & $2.5667 \mathrm{~A}$ & 2.5000 & 2.5600 & 0.0764 & 2.9757 \\
V2 & $3.1233 \mathrm{~B}$ & 3.1000 & 3.1500 & 0.0252 & 0.8057 \\
V3 & $3.3167 \mathrm{C}$ & 3.2000 & 3.4000 & 0.1041 & 3.1382 \\
V4 & $1.2467 \mathrm{D}$ & 1.2100 & 1.2900 & 0.0404 & 1.2900 \\
\hline
\end{tabular}

LSD: SEC: 0.0562; CTV: 2.306; CVC: 0.1295

- All the mean values are the result of four replications

- All 4 means are significantly different from one another

Table 7. Mean detection of crude fat level of dried apricot.

\begin{tabular}{llllll}
\hline Varieties & Mean & Min & Max & S.D & CV \\
\hline V1 & $1.6500 \mathrm{~A}$ & 1.5500 & 1.8000 & 0.1323 & 8.0174 \\
V2 & $1.2367 \mathrm{~A}$ & 1.2200 & 1.2500 & 0.0153 & 1.2352 \\
V3 & $1.3600 \mathrm{~B}$ & 1.3500 & 1.3800 & 0.0173 & 1.2736 \\
V4 & $1.7333 \mathrm{~B}$ & 1.6500 & 1.8000 & 0.0764 & 4.4063 \\
\hline
\end{tabular}

LSD: SEC: 0.0631; CTV: 2.306; CVC: 0.1454

- All the mean values are the result of four replications

- All the means carrying same alphabets are non significant at alpha $=0.05$

Table 8. Mean detection of total dry solid of dried apricot.

\begin{tabular}{llllll}
\hline Varieties & Mean & Min & Max & S.D & CV \\
\hline V1 & $89.300 \mathrm{~A}$ & 88.950 & 86.950 & 0.3122 & 0.3497 \\
V2 & $87.370 \mathrm{~B}$ & 87.250 & 87.550 & 0.1587 & 0.1817 \\
V3 & $86.267 \mathrm{C}$ & 86.200 & 86.350 & 0.0764 & 0.0885 \\
V4 & $88.257 \mathrm{D}$ & 88.000 & 88.520 & 0.2601 & 0.2947 \\
\hline
\end{tabular}

LSD: SEC: 0.1808; CTV: 2.306; CVC: 0.4170

- All the mean values are the result of four replications

- All 2 means are significantly different from one another

Table 9. Mean detection of ascorbic acid level of dried apricot.

\begin{tabular}{llllll}
\hline Varieties & Mean & Min & Max & S.D & CV \\
\hline V1 & $17.477 \mathrm{~A}$ & 17.000 & 17.880 & 0.4446 & 2.5437 \\
V2 & $16.263 \mathrm{~B}$ & 16.000 & 16.540 & 0.2702 & 1.6617 \\
V3 & $15.233 \mathrm{C}$ & 15.000 & 15.450 & 0.2255 & 1.4801 \\
V4 & $14.200 \mathrm{D}$ & 14.000 & 14.350 & 0.1803 & 1.2696 \\
\hline
\end{tabular}

LSD: SEC: 0.2429; CTV: 2.306; CVC: 0.1454

- All the mean values are the result of four replications

- All 4 means are significantly different from one another

Table 10. Mean detection of taste level of dried varieties of apricot.

\begin{tabular}{llllll}
\hline Varieties & Mean & Min & Max & S.D & CV \\
\hline V1 & $6.200 \mathrm{~A}$ & 6.000 & 6.4000 & 0.2000 & 3.2258 \\
V2 & $7.400 \mathrm{~B}$ & 7.200 & 7.6000 & 0.2000 & 2.7027 \\
V3 & 6.600 & 6.400 & 6.8000 & 0.2000 & 3.0303 \\
V4 & 6.366 & 6.200 & 6.5000 & 0.1528 & 2.3993 \\
\hline
\end{tabular}

LSD: SEC: 0.1546; CTV: 2.306; CVC: 0.3564
- All the mean values are the result of four replications

- All the means carrying same alphabets are non significant at alpha $=0.05$

Table 11. Mean detection of color level of dried varieties of apricot.

\begin{tabular}{llllll}
\hline Varieties & Mean & Min & Max & S.D & CV \\
\hline V1 & $6.433 \mathrm{~A}$ & 6.0000 & 6.8000 & 0.4041 & 6.2820 \\
V2 & $7.233 \mathrm{~B}$ & 7.0000 & 7.5000 & 0.2517 & 2.7778 \\
V3 & $6.400 \mathrm{C}$ & 6.2000 & 6.6000 & 0.2000 & 3.1250 \\
V4 & $8.200 \mathrm{C}$ & 8.0000 & 8.4000 & 0.2000 & 4.8238 \\
\hline
\end{tabular}

LSD: SEC: 0.2261; CTV: 2.306; CVC: 0.5213

- All the mean values are the result of four replications

- All the means carrying same alphabets are nonsignificant at alpha $=0.05$

Table 12. Detection of texture level of dried varieties of apricot.

\begin{tabular}{llllll}
\hline Varieties & Mean & Min & Max & S.D & CV \\
\hline V1 & $6.500 \mathrm{~A}$ & 6.4000 & 6.6000 & 1.1000 & 1.5385 \\
V2 & $7.200 \mathrm{~B}$ & 7.0000 & 7.4000 & 0.2000 & 2.7778 \\
V3 & $6.000 \mathrm{C}$ & 5.8000 & 6.2000 & 0.2000 & 3.3333 \\
V4 & $6.333 \mathrm{BC}$ & 6.0000 & 6.6000 & 0.3055 & 4.8238 \\
\hline
\end{tabular}

LSD: SEC: 0.1748; CTV: 2.306; CVC: 0.4031

- All the mean values are the result of four replications

- All the means carrying same alphabets are nonsignificant at alpha $=0.05$

Table 13. Detecion of over all acceptability level of dried apricot.

\begin{tabular}{llllll}
\hline Varieties & Mean & Min & Max & S.D & CV \\
\hline V1 & $6.566 \mathrm{~A}$ & 6.400 & 6.800 & 0.208 & 3.170 \\
V2 & $7.200 \mathrm{~B}$ & 7.000 & 7.400 & 0.200 & 2.777 \\
V3 & $6.400 \mathrm{~B}$ & 6.200 & 6.600 & 0.200 & 3.125 \\
V4 & $6.333 \mathrm{~B}$ & 6.000 & 6.600 & 0.305 & 4.823 \\
\hline
\end{tabular}

LSD: SEC: 0.1900; CTV: 2.306; CVC: 0.4382

- All the mean values are the result of four replications

- All the means carrying same alphabets are nonsignificant at alpha $=0.05$

\section{Discussion}

The standard physical, chemical and sensory parameters of different varieties of dried apricot were analyzed in the present study. These parameters play a vital role for the quality of the fresh and dried fruits the importance of the physio-chemical characteristics of the fruits can be judged from the fact that Xie and Zhao (2004) stated that the physio chemical attributes of fruit play an important role in determination of the behavior of fruit, nature of fruit and their response to handling and processing. For food engineers, horticulturists and food technologists these attributes are very important as they together seek out for developing satisfactory handling, processing and harvesting technologies.

The sensory parameters include in this study are taste, color, texture and overall acceptability. Present study is carried out on four different varieties of dried apricots i.e. (V1), (V2), (V3) and (V4) forMargulam, Halman, Habi and 
khakas respectively.

It is concluded from above discussion that different dried varieties of apricots contributes nutrients and macro and micro minerals provide energy and also have medicinal importance. The discussion suggest that Halman with appreciable amount of moisture content, total ash content, $\mathrm{pH}$, ascorbic acid, crude fiber and crude fat could be a good source of nutrition as compared to other varieties.

The color, taste, texture and overall acceptability were also examined in this study; it may be concluded on judge's remarks that variety (V2) Halman has got better sensory attributes as compared to other varieties.

Other chemical properties i.e. moisture, crude fat, crude fiber, Total Soluble Solids, Ash, pH, Titratable Acidity, and Ascorbic Acid were also analyzed. The moisture content is one of the most imperative properties and is generally measured in different food commodities. Storage stability, better processing conditions and quality of food are related with its low moisture content. The mean values for varieties were $10.00,12.477,11.423$ and 11.137 for Margulam, Halman, Habi and khakas respectively. The results were in close agreement with the findings of Hussain et al. (2010). They interpret that moisture content of dried apricots varies from $10.61 \pm 0.90$ to $15.10 \pm 0.65$. Ash content is the mineral concentration in certain food product, Higher the ash content higher is the amount of minerals. Mean values of ash content for varieties were $3.336,3.200,3.1267$ and 2.4567 for Margulam, Halman, Habi and khakas respectively. Current results for ash content are within the limits according to the findings reported by Hussain et al., (2010). They found that the ash content ranged from $2.62 \pm 0.11$ to $4.86 \pm 0.13$ for five varieties of dried apricot grown in Northern areas of Pakistan. $\mathrm{pH}$ has an effect on color expression and anthocyanin, particularly in aqueous solution. Due to change in $\mathrm{pH}$ color loses in fruits and vegetables may occur. Mean values of $\mathrm{pH}$ for varieties ranged from 4.3833, 4.2667, 4.2500 and 4.4333 for Margulam, Halman, Habi and khakas respectively. pH 3.65 was reported in a study by (Witthuhn et al.,2005). In another previous study $\mathrm{pH} 3.9$ was recorded in dry apricot by (Monica et al., 2009). This difference may be due to the variety and cultivation area. Fiber decreases risk of many disorders like diabetes, cardiovascular diseases, constipation, and obesity. Crude fiber has gained a little food value but it provides bulk to the foods and also helps to regulate some physiological functions. The mean values for varieties were $2.5667,3.1233,3.3167$, and 1.2467 for Margulam, Halman, Habi and khakas respectively. These results are closely linked with the findings of (Hussain et al.,2010). They reported crude fiber in dried apricot varieties of Gilgit Baltistan were ranged from 2.27-3.26.

Fats are esters of saturated and unsaturated fatty acids with glycerol. They are solid at room temperature; they are an essential source of energy. They play an important role in physical characteristics such as mouth feel, flavor, texture and appearance. Mean value for varieties was ranged 1.6500, $1.2367,1.3500$ and 1.7333 . These results were similar to the findings reported by Hussain et al., (2010). The mean values of dry solids for different varieties were 89.300, 87.370, 86,267 and 88.258 for Margulam, Halman, Habi and Khakas respectively. Maximum value reported was 89.300 of Margulam and minimum valve was 86.267 of Habi. The results of current study were similar by the findings of (Monica et al., 2008).

Fruit and vegetables supply ascorbic acid in human diets. It is important for tissue building and energy transfer and manufacture of hormones. The mean values were 17.477, 16.263, 15.233, and 14.200 for Margulam, Halman, Habi and Khakas respectively. Hence, the maximum value was reported in Margulam whereas minimum in Khakas. The results of study were close agreement with the findings of (Hussain et al., 2010).

\section{Conclusion}

Different dried varieties of apricots contribute nutrients and macro and micro minerals provide energy and also have medicinal importance. The discussion suggest that Halman with appreciable amount of moisture content, total ash content, $\mathrm{pH}$, ascorbic acid, crude fiber and crude fat could be a good source of nutrition as compared to other varieties. Apricot is cheaper source of nutrition, energy which common men can effort to purchase. These dried varieties are stable at room temperature for long period and do not require any storage technique.

\section{Acknowledgement}

Authors wish acknowledge all contributors who give their input during the research period and special thanks Department of Agriculture and Food Technology, Karakoram International University, Gilgit, Pakistan.

\section{References}

[1] AKRSP, (1999). AKHA KHAN RURAL SUPPORT PROGRAME. Annual progress report at: http:/www.nlh.no/noragric/projects/AKRSP/default.htm.

[2] A.O.A.C. (2006). Official method of analysis. The association of Official Analytical Chemists. Arlington, Virgina, USA.

[3] Ali, S., T. Masud and K.S. Abbasi. (2011). Physico-chemical characteristics of apricot (Prunus armeniaca L.) grown in Northern Areas of Pakistan. Sci. Hort. 130(2): 386-392.

[4] Anonymous, (2004). Solar drying technology for northern areas. Available at http:/www.dawn.com/2004/08/01/local13.html.

[5] Barsotti, L., P. Merle and J. C. Cheftel. (1999). Food processing by electric fields: Physical aspects. J. Food Rev. Int., 15: 163-180.

[6] Enomoto, S.,K. Yanaoka, H. Utsunomiya, T. Niwa, K. Inada, H. Deguchi, K. Ueda, C. Mukoubayashi, I. Inoue, T. Maekita, K. Nakazawa, M. Iguchi, H. Tamai, M. Fujishiro, M. Oka and M., Ichinose, (2010). Inhibitory effects of Japanese Apricot, (Prunus Mume Siebold ET Zucc.; Ume), on Helicobacter pylori-related chronic gastritis. Nat. Rev. Gastroenerol. Hepatol. 7, 478. 
[7] FAO. (2008).Food and Agriculture Organization of the United Nations. http://extension.usu.edu/files/foodpub/fn330.pdf.

[8] Faqir, M.A., A. Saeed and D. Maqam. (2004). Storage effect on physiochemical and sensor characteristics of dried apricot jam. Pak. J. Food. Sci. 14(1-2): 43-47.

[9] G.O.P. (Government of Pakistan). (2008). Fruit, vegetables and condiments statistics of Pakistan. Ministry of Food, Agriculture and Livestock, Islamabad.

[10] Leccese, A., S. Bartolini and R. Viti. (2007). Total antioxidant capacity and phenolics content in apricot fruits. Int. J. Fruit Sci. 7 (2): 3-16.

[11] Lichou, J. (1999). Apricot: shelf life and fruit quality. Mitteilungen-Klosterneburg. Rebe-Und-Wein, Okstban-UndFruchteverwertung, 49(6): 204-205.

[12] Madrau, M., A. Piscopo, A. Sanguinetti, A. Del Caro, M. Poiana and F. Romeo. (2009). Effect of drying temperature on polyphenolic content and antioxidant activity of apricots. European Food Research Technology, 228, 441-448. Mignani, I. and D. Bassi. (2000). Rootstock influence on ripening quality of apricot fruits. Rivista-di -Frutticoltura-eOrtofloricoltura. 62(4): 34-39.
[13] PBS (Pakistan Bureau of Statistics) (2011). Fruit, Vegetable and Condiments Statistics of Pakistan. Ministry of Economics Affair and Statistics of Pakistan.

[14] Samann, H. (1991). Suitability of indigenous fruit. Cultivars for the production of dried fruit. MitteilungenKklosterneubury Rebe Und Wein, Obstbau and Fruchtever Wertung. 41 (3): 127-133.

[15] Shahidi, F. and M. Naczk. (1995). Food Phenolics Sources, Chemistry, Effects and Applications. Lancaster, Technimic publishing Co. p. 1-5, 95.

[16] Shi, X.Q. and P.M. Fito. (2004). Mass transfer in vacuum osmotic dehydration of fruits: a mathematical model approach. Lebensmittel Wissenschaft and Technol. 27: 67-72.

[17] Singh, J., S. Paul and V.K. Thapar. (1990). Polyethylene sheet cover as a substitute of glass top in solar cabinet dryer. J. of Res, P. Agri Uni, 27, 108-116.

[18] Taiwo, K. A., A. Angersbach, B. I. O. Ade-Omowaye and D. Knorr. (2001). Effects of pre-treatment on the diffusion kinetics and some quality parameters of osmotically dehydrated apple slices. J. Agri. Food. Chem. 49: 2804-2811. 